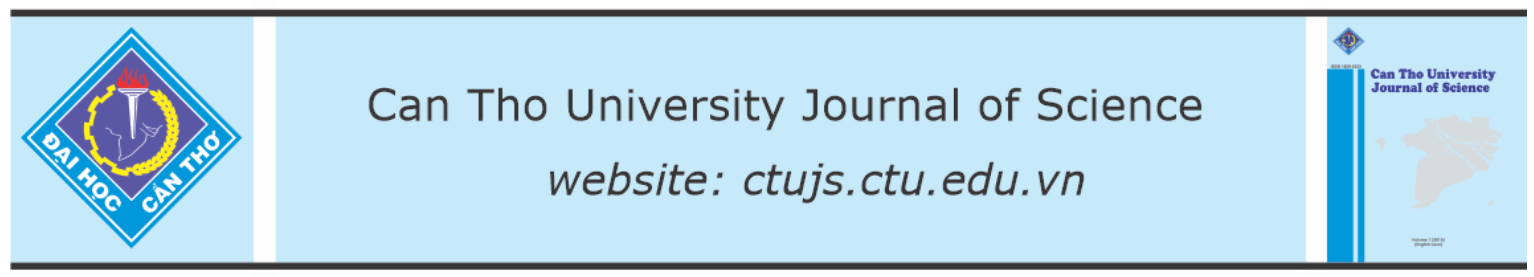

DOI: 10.22144/ctu.jen.2021.040

\title{
Synthesis of lignin-based phenol-formaldehyde adhesive - A sustainable alternative to petrochemical
}

Nguyen Thi Nhu $\mathrm{Y}^{1}$, Nguyen Thi Yen Nhi ${ }^{1}$, Tran Thi Minh Thu ${ }^{1}$, Nguyen Thi Ven ${ }^{2}$, Tran Nguyen Phuong Lan $^{2}$ and Luong Huynh Vu Thanh ${ }^{2 *}$

${ }^{I}$ Can Tho University of Technology, Viet Nam

${ }^{2}$ Can Tho University, Viet Nam

*Correspondence: Luong Huynh Vu Thanh (email: Ihvthanh@ctu.edu.vn)

\section{Article info.}

Received 05 May 2021

Revised 17 Jun 2021

Accepted 25 Jun 2021

\section{Keywords}

Lignin-based adhesive, Coir pith, lignin-based phenolformaldehyde adhesive, Phenolic resin

\begin{abstract}
This study is to investigate the capability of producing lignin-based phenolformaldehyde adhesive (LBPFA) with lignin derived from coir pith collected in the Mekong Delta, Viet Nam. The LBPFA synthetic process underwent non chemical modifications to minimize petrochemicals and energy. Effective factors as reaction time, reaction temperature and various lignin contents of phenol substitution were examined. Physical, chemical and thermal properties containing formaldehyde content, viscosity, solid content, Fourier transformed infrared spectroscopy (FTIR), differential scanning calorimetry (DSC), tensile strength, tensile modulus and tensile strain were conducted. LBPFA was successfully synthesized at various levels of lignin contents substituting for phenol. The LBPFA's parameters were in accordance with GB/T14372-2006 standard. The optimum reaction time, reaction temperature and lignin replacement content for LBPFA synthesis process were identified at 180 minutes, $90^{\circ} \mathrm{C}$ and $40 \% \mathrm{wt} / \mathrm{wt}$, respectively. The LBPFA showed the highest dry and wet tensile strengths of $14.42 \mathrm{MPa}$ and 7.66 MPa on wooden boards compared to corresponding figures of commercial resin with $2.98 \mathrm{MPa}$ and $0 \mathrm{MPa}$, respectively. For plywood, bending strength shown in LBPFA and commercial adhesive were $15.97 \mathrm{MPa}$ and $20.16 \mathrm{MPa}$, respectively.
\end{abstract}

\section{INTRODUCTION}

Coir pith is a common agricultural by-product in Mekong Delta especially in Ben Tre province. Due to low value, coir pith was not utilized completely, which resulted in polluted air and water environment at coconut fiber processing areas (Luong et al., 2017; Nguyen et al., 2018). Lignin is one of the main components of plants, acting as a natural adhesive polymer in plant cell walls, increasing mechanical strength and waterproofing. Lignin is a heterogeneous polymer containing several function groups: hydroxyl, phenolic and ester groups. Its physical and chemical properties are highly dependent on biomass sources, locations and extraction methods (Mansori et al., 2006; Duval et al., 2014).

Poly (phenol-formaldehyde) resins are being used in about one-tenth of all plywood and particle board industries. The outstanding performance of phenolic resins are high strength, long-term mechanical and thermal stability, low toxicity, low formaldehyde content, high water resistance, low phenolic swelling, excellent electrical and thermal insulation. The drawback of these resin is that it is toxic due to 
using phenol, ingredients depending on petrochemical resources, high manufacturing cost, hardening more slowly than the amino plastic (Wang et al., 2009; Zakaria et al., 2015).

Fluctuations in oil price caused by over-explored natural resources and concerns about chronic exposure to phenol of workers during the manufacturing process have been the main reasons boosting many researchers studying on replacing phenol by biomass during the last three decades (Mainka et al., 2015). Many studies showed that lignin formula has capability to replace phenol in producing Phenol-Formaldehyde Resin (Cetin et al., 2003; Tejado et al., 2007; Hemmila et al., 2013; Norgren et al., 2013; Yang et al., 2015). This method is not only reducing toxicity but also decreasing manufacturing cost and environmental pollution (Derek, 2008). Lignin was used to replace phenol in manufacturing phenol formaldehyde adhesive in many researches: lignin could be used as an alternative $(10-100 \%)$ in the production of phenol-formaldehyde or epoxy resins (Tejado et al., 2007). In detail, phenol formaldehyde adhesive was synthesized from organosolv pine lignin (Wang et al., 2009), biorefinery technical lignin (Liitia et al., 2014). These processes successfully synthesized phenolic colloids by substituting 5-50\% lignin with different sources for phenol. However, designed processes were divided into several stages which were time-consuming, used ure as a stabilizer and the quality of adhesive and its durability have not been assessed yet (Mainka et al., 2015).

Lignin is accounted for $28.58 \%$ (wt/wt) coir pith with soda extracting method. Coir pith lignin has molecular mass of $27.6 \mathrm{kDa}$ which is much greater than that figure of lignin from hardwood, softwood and grass, so the content of phenolic hydroxyl group in coir pith lignin is also greater. This proves coir pith lignin having potential applications in chemical synthesis and producing phenolic resins (Nguyen et al., 2017).

\section{MATERIALS AND METHODS}

\subsection{Materials}

Alkali lignin particles with size range of some tens to hundreds micrometer and average molecular weight of $27.6 \mathrm{kDa}$ were extracted and purified from coir pith in Mekong Delta, Viet Nam according to a previously reported method (Nguyen et al., 2018). Other chemicals: $\mathrm{NaOH}(96 \%), \mathrm{H}_{2} \mathrm{SO}_{4}(95-98 \%)$, $\mathrm{HCl}(36-38 \%), \mathrm{HCHO}(37-40 \%), \mathrm{C}_{6} \mathrm{H}_{5} \mathrm{OH}$ and $\mathrm{NH}_{2} \mathrm{OH} . \mathrm{HCl}(98.5 \%)$ purchased from Xilong
Scientific, China and distilled water obtained from Chemical engineering laboratory were used.

\subsection{Preparation of lignin-based phenol- formaldehyde adhesive (LBPFA) solutions}

The general process of producing LBPFA and identifying its characterizations were briefly shown in Fig. 1. The extracted lignin was used to replace phenolic group in synthesis of LBPFA. In Fig.2, the procedure of LBPFA synthesis was presented in detail. Firstly, LBPFA was prepared by replacing phenolic ingredient with different amounts of lignin $(10,20,30,40,50 \% \mathrm{wt} / \mathrm{wt})$. The weight ratios of formaldehyde to phenol (including both phenol and lignin) and of phenol to $\mathrm{NaOH}$ were constantly kept at 4:3 (wt/wt) (equaling to 1.53:1.0 in molar ratio) and 10:3 (wt/wt), respectively, for all trials. Then, lignin was dissolved in $\mathrm{NaOH} 1 \mathrm{M}$ solution inside a three-necked flask, temperature was gradually increased to $70^{\circ} \mathrm{C}$ with continuous stirring using plastic coated magnets so that lignin could be completely dissolved. Adding adequate volume of formaldehyde (37\%), adjusting $\mathrm{pH}$ in the range of $10-12$ by $\mathrm{NaOH} 0.5 \mathrm{M}$ were the following steps. Increasing temperature to $\mathrm{T}^{0} \mathrm{C}$ during $\mathrm{t}$ time (minutes) ( $\mathrm{T}$ and $\mathrm{t}$ are the surveyed parameters Table 1) was next controlled. After that, the system was cool to room temperature and the final product was collected.

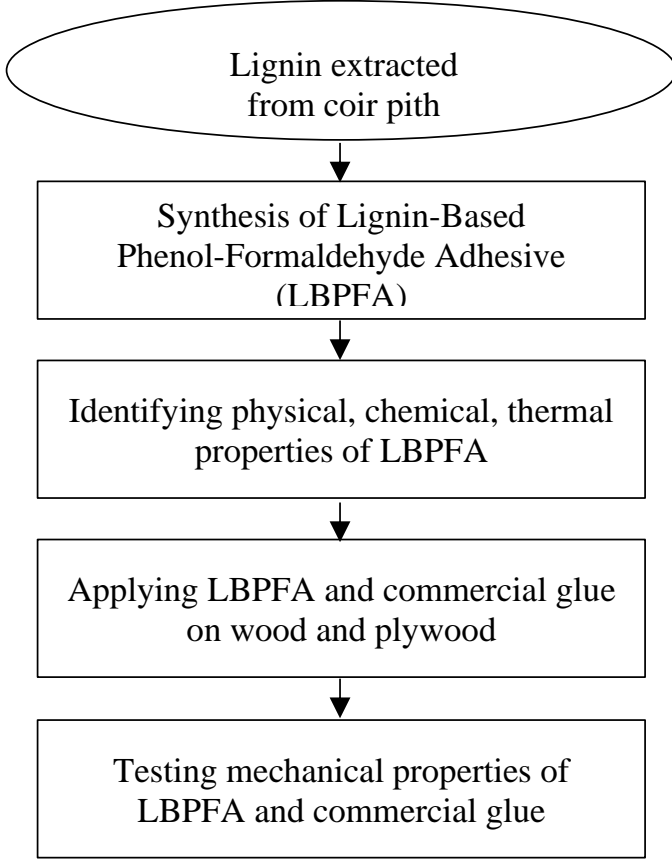

Fig. 1. Process of producing and identifying LBPFA's characterizations 


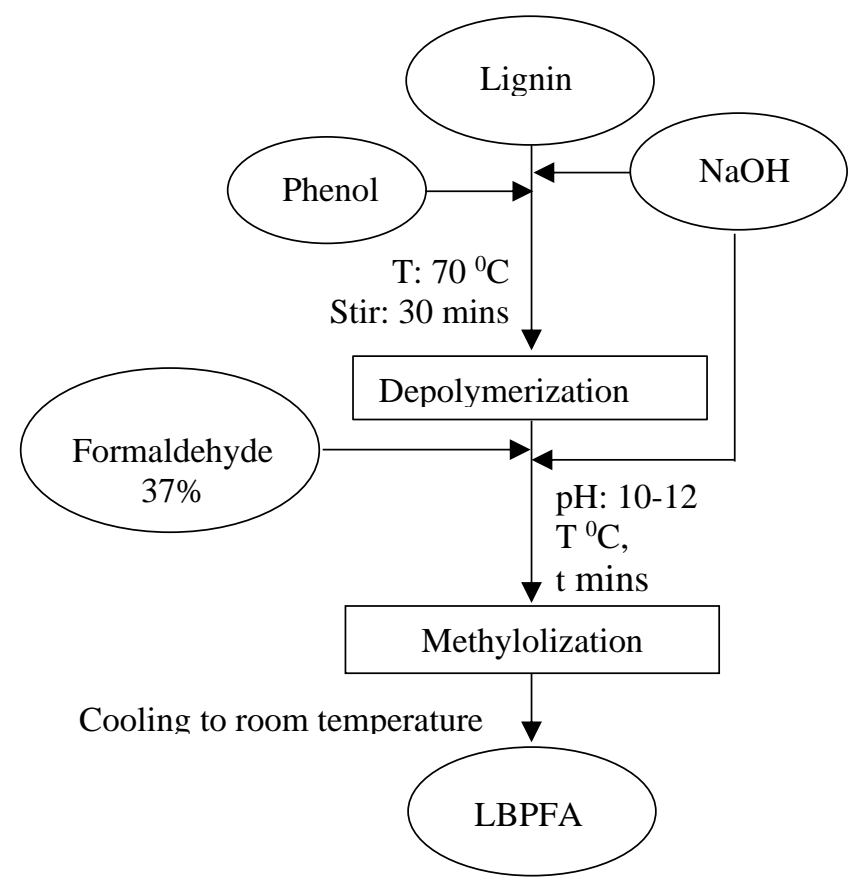

Fig. 2. Synthesis of lignin-based phenol-formaldehyde adhesive process

Table 1. Examined parameters: replacing lignin content on phenol $(\% \mathrm{wt} / \mathrm{wt})$, time and temperature reactions

\begin{tabular}{crr}
\hline \% Lignin & Time (minutes) & Temperature $\left({ }^{\mathbf{0}} \mathbf{C}\right)$ \\
\hline 0 & 60 & 80 \\
20 & 90 & 90 \\
30 & 120 & 100 \\
40 & 150 & \\
50 & 180 & \\
\hline
\end{tabular}

\subsection{Determination of LBPFA's characterizations}

\subsubsection{Formaldehyde content}

Titration method was applied based on the reaction of formaldehyde with hydroxylamine hydrochloride $\mathrm{NH}_{2} \mathrm{OH} . \mathrm{HCl}$ to form $\mathrm{HCl}$ according to ISO 9397: 1997 standard.

\subsubsection{Viscosity}

The viscosity was measured by the handheld viscometer TMVM 1, SKF at Biotechnology Research and Development Institute, Can Tho University.

\subsubsection{Thermal properties}

Thermal stability of coir pith lignin-based adhesive was tested by DSC differential heat measurement method with NETZSCH TG209 F3 at College of Engineering Technology, Can Tho University. The heating rate was $10^{\circ} \mathrm{C}$.minute ${ }^{-1}$ from room temperature to $200^{\circ} \mathrm{C}$ in a nitrogen atmosphere with a flow rate of $10 \mathrm{~mL}$.minute ${ }^{-1}$. Samples were dried at $50^{\circ} \mathrm{C}$ for 24 hours and stored in desiccator before conducting the analysis.

\subsubsection{FT-IR analysis of LBPFA}

The specific bondings of synthetic LBPFA were analyzed by Nicolet 6700 FT-IR Thermo Scientific at the number of waves from 4000 to $500 \mathrm{~cm}^{-1}$ at College of Natural Sciences, Can Tho University.

\subsubsection{Solid content}

Solid content was determined by drying samples at $105^{\circ} \mathrm{C}$ for 4 hours in Memmert UF260.

\subsubsection{Mechanical properties}

The Panstone P-100 PCD hot press was used to press samples, the machine has 2 components: the hydraulic unit for adjusting pressure and the resistance for regulating the heat.

Mechanical measurements including tensile strength, tensile modulus, tensile strain and bending strength of the samples were tested by Zwick/Roell BDO-FB050TN.

\subsection{Preparation of lap shear samples}

Tests were carried out for each type of natural timber and artificial plywood with both coir pith lignin- based phenol-formaldehyde adhesive 
(LBPFA) and a popular commercial adhesive (X'traseal $\mathrm{x}$ 'bond construction adhesive). Each adhesive was applied on 5 samples in correspondence with one type of wood Melaleuca timber and artificial plywood which were purchased at A Dat carpenter workshop at Can Tho city for all tests. Samples' surface and moisture were firstly pretreated to improve the adhering process. Next, preparation of $0.15 \mathrm{~g}$ of each adhesive formulation was applied on the area of $25 \mathrm{~mm} \times 25 \mathrm{~mm}$ at the end section of melaleuca timber and plywood samples $(100 \mathrm{~mm} \times 25 \mathrm{~mm} \times 7 \mathrm{~mm})$. Then, two pieces of wood were stuck by hand and put them into the hot-pressing machine (Panstone P-100 PCD) with pressing temperature, the time and the pressure at $100{ }^{0} \mathrm{C}, 3$ minutes and $1 \mathrm{MPa}$, respectively. Finally, the samples were taken out and stored at room temperature for 3 days to stabilize before conducting mechanical tests.

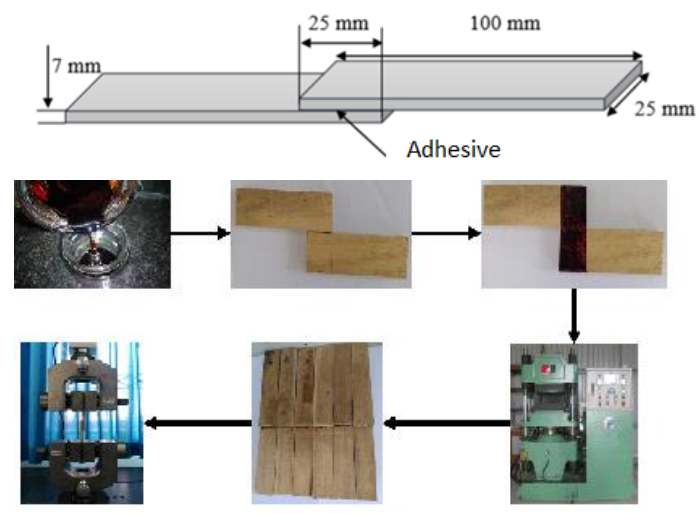

Fig. 3. Illustration of the lap shear strength specimen

\subsection{Determination of mechanical properties}

The ASTM D5868-01 and ASTM D3434 standards were applied for dry and wet tensile strengths,

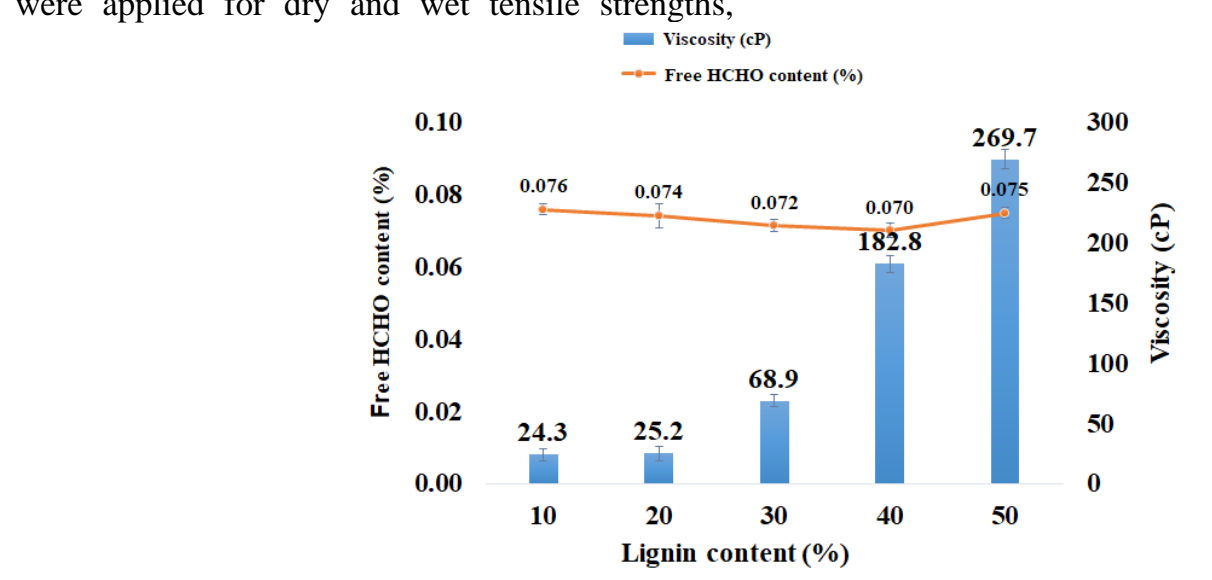

Fig. 4. Effect of lignin content to viscosity and free HCHO content respectively. Generally, the samples were submerged in boiling water in 4 hours, then were dried at $65 \pm 3^{\circ} \mathrm{C}$ for 20 hours. After that these samples were submerged again in hot water for the next 4 hours before mechanical properties were checked. In the case of plywood, bending strength was mostly conducted by TCVN 7756-6:2007 standard.

\section{RESULTS AND DISCUSSION}

\subsection{Effect of substituted lignin content on viscosity and free formaldehyde content}

the lignin content of 10 and $20 \%$, hovering at $25 \mathrm{cP}$ and rapidly increased at those of 30,40 and 50\% at 68.9, 182.8 and $239.7 \mathrm{cP}$, respectively. These viscosities changed at the same conditions (time, temperature, and catalyst) indicated the ability to create resin differently. This can explain that the reactions are more effective when the amount of appropriate catalyst is sufficient to dissolve lignin and $\mathrm{PF}$ in certain synthesis environment.

The impact of free formaldehyde content versus lignin content was also illustrated. The lowest free formaldehyde content got the minimum at $40 \%$ replacing lignin. This could explain the catalyst amount was insufficient at the higher replacing level (50\%). Combination of the capability of forming resin and the free formaldehyde content in Fig. 4, $40 \%$ lignin was selected as an optimal condition for following surveys. However, the goal of study is examination to replace phenol by lignin as much as possible and resin performance applied on wood board. Therefore, chosen values that meet the standard GB /T 14732-2006 for the next surveys were 30 - 50\% lignin. 
Effect of the lignin content is shown in Fig. 4. The viscosities of solutions increased proportionally according to the growth of lignin content on phenol. In fact, the viscosities changed almost negligibly at

\subsection{Effect of temperature on adhesive forming capability}

Temperature had a great influence on the reaction rate. Fig. 5 showed that when temperature was $80^{\circ} \mathrm{C}$ the solution presented a low viscosity of $31 \mathrm{cP}$ and high free formaldehyde content. However, the viscosity increased slightly to $69 \mathrm{cP}$ and rapidly to $198 \mathrm{cP}$ as the temperature of reaction was $90^{\circ} \mathrm{C}$ and $100^{\circ} \mathrm{C}$, respectively. In the meantime, free formaldehyde contents at these two temperatures was mostly the same, $0.072 \%$ and $0.068 \%$, respectively. It is known that low or high viscosity can be a drawback to perform the adhesive to wood boards. Besides, low free formaldehyde represented for high replacement of phenolic groups to the structure of the resin. However, the adhesive was partly solidified after these exothermic reactions ended at the reaction temperature of $100{ }^{\circ} \mathrm{C}$. This could be explained by appearance of overheating or adhesive temperature reaching the glass transition temperature of lignin $\left(\mathrm{Tg}: 115.6^{\circ} \mathrm{C}\right)$ or both of them. Therefore, $90^{\circ} \mathrm{C}$ was selected as the optimal temperature for the synthesis process and following experiments.

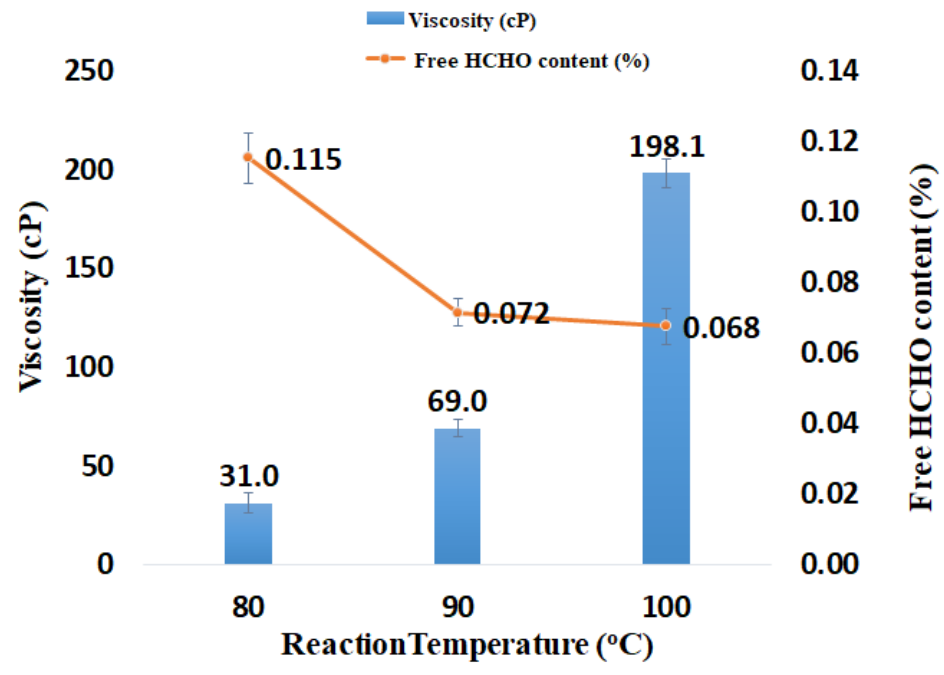

Fig. 5. Effect of temperature on LBPFA forming capability

\subsection{Effect of reaction time on resin forming process}

The cross-linking reaction time always accounts for a high number of total reaction time. The total reaction time for the LBPFA synthetic process consists of resolution, creating methylol groups on the benzene ring of lignin and phenol molecules, and condensation reaction (splitting water, creating methylene bonds). It is considered that a short runtime is not enough to create cross linkages. However, a long run-time leads to bonding reactions being increasingly tightened together and the solution becoming hard.

The effect of reaction time on viscosity and free HCHO content were presented in Fig. 6. The range of reaction time was set from 60 to 180 minutes. In Fig. 6(a), at the first 60-minute viscosity of the adhesive was unchanged at $31.10 \mathrm{cP}$ at various lignin contents (30, 40 and 50\%). Nevertheless, when reaction time increased to 120 minutes, the viscosity of the adhesive with $30 \%$ lignin slightly rose to $32.81 \mathrm{cP}$ while that of the adhesive with $40 \%$ and $50 \%$ lignin significantly increased to $89.64 \mathrm{cP}$ and $136.02 \mathrm{cP}$. If the reaction was continually kept for 60 minutes more, the viscosity of the adhesive with $30 \%$ lignin moderately increased by $36.14 \mathrm{cP}$. In the meantime, for $40 \%$ and $50 \%$ lignin, the viscosity of the adhesive rocketed to 182.77 and $284.33 \mathrm{cP}$, respectively. The reason for a significant increase in the period of the last 60 minutes could be that cross-linking reactions considerably happened in the period of 60 to 120 minutes and the reactions mainly occurred in the period of 120 to 180 minutes. It was noticeable that with 50\% lignin and run-time over 180 minutes, the adhesive became a thickened liquid and then solid. The appearance of LBPFA with synthetic conditions: $50 \%$ lignin, reaction temperature of $90^{\circ} \mathrm{C}$ and reaction time of 180 minutes and more than 180 minutes was illustrated 
in Fig. 7. This is consistent with the theoretical basis given. Therefore, reaction time in range from 120 to 180 minutes was chosen as the appropriate time for the LBPFA synthetic process.

In contrast to viscosity, free formaldehyde content showed a reduction when reaction time increased showing in Fig. 6(b). When reaction time varied from 60 to 180 minutes, free formaldehyde content of the adhesive with 30,40 and $50 \%$ lignin decreased from 0.120 to $0.082 \%, 0.250$ to $0.073 \%$ and 0.270 to $0.082 \%$, respectively. This result was completely consistent to the previous studies (Wang et al., 2009; Kalami et al., 2017).

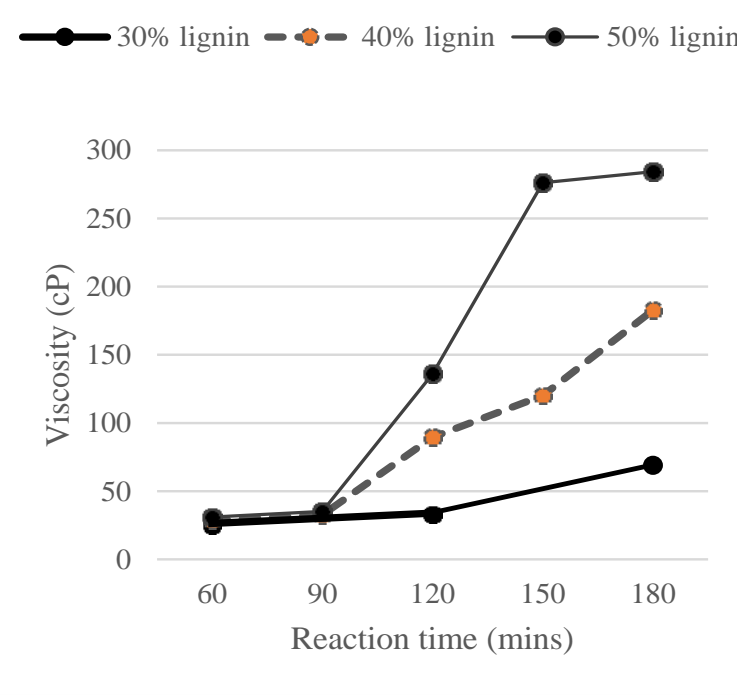

(a)

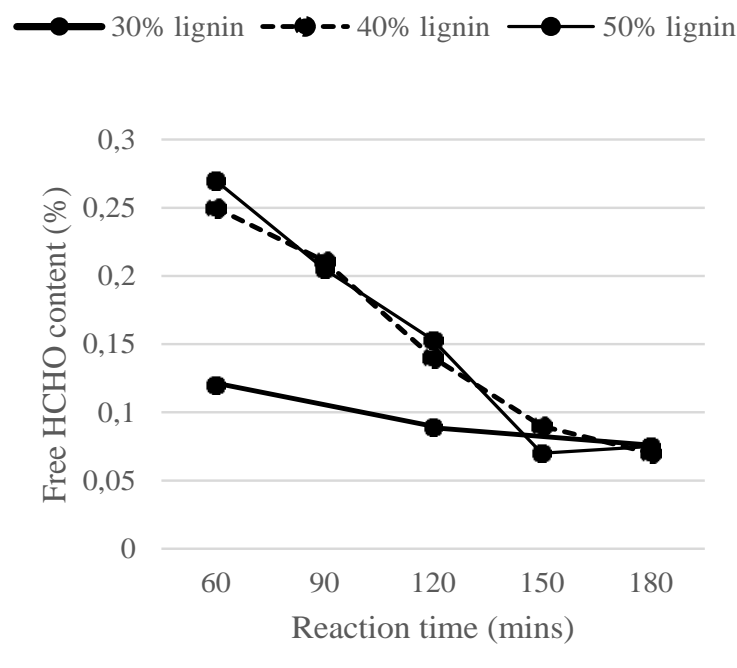

(b)

Fig. 6. Effect of reaction time on (a) viscosity and (b) free HCHO content
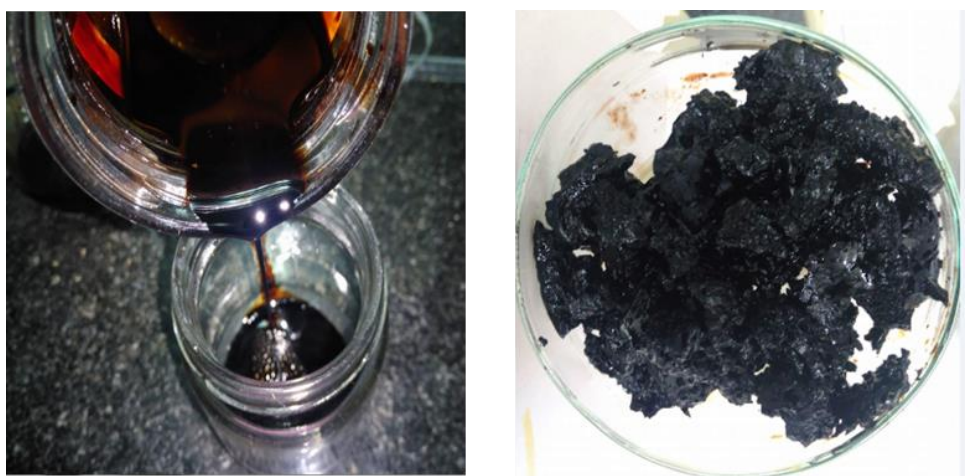

Fig. 7. Appearance of LBPFA at different reaction time: (a) 180 minutes and (b) more than 180 minutes

\subsection{Adhesive parameters}

Basic physical properties of lignin including free formaldehyde content, solid content, $\mathrm{pH}$ and viscosity were presented in Table 2 . In fact, for free $\mathrm{HCHO}$ content the longer reaction time is the lower free $\mathrm{HCHO}$ content is. Moreover, when the percentage of lignin increased and reaction time kept long, solid content straightly increased from $38.44 \%$ to $53.38 \%$. Similar to free HCHO content,
$\mathrm{pH}$ of the LBPFA slightly decreased by less than 1 unit and the value of $\mathrm{pH}$ of the adhesive was moderately controlled. In terms of viscosity, the value of this parameter also increased straightly like solid content, but the gap was significant. In detail, viscosity of the adhesive at reaction time of 180 minutes was $68.9,182.8$ and $284.3 \mathrm{cP}$ with lignin replacement of 30,40 and $50 \%$, respectively. Through experimental results, the adhesive's parameters met the GB/T 14372 - 2006 standard. 
Table 2. Parameters of coir pith LBPFA at synthesis temperature of $90^{\circ} \mathrm{C}$

\begin{tabular}{|c|c|c|c|c|c|}
\hline $\begin{array}{c}\text { Lignin content, } \\
\% \\
\end{array}$ & $\begin{array}{c}\text { Reaction time, } \\
\text { minutes }\end{array}$ & $\begin{array}{c}\text { Free } \mathrm{HCHO} \\
\text { content, \% }\end{array}$ & $\begin{array}{c}\text { Solid content, } \\
\% \\
\end{array}$ & pH & $\begin{array}{c}\text { Viscosity, } \\
\text { cP }\end{array}$ \\
\hline \multicolumn{2}{|c|}{ GB/T 14372} & $\leq 0.3$ & $\geq 35$ & $\geq 7$ & $\geq 60$ \\
\hline 30 & 180 & 0.072 & 38.44 & 11.03 & 68.9 \\
\hline \multirow{3}{*}{40} & 120 & 0.140 & 39.11 & 10.95 & 89.60 \\
\hline & 150 & 0.090 & 41.55 & 10.17 & 120.1 \\
\hline & 180 & 0.070 & 48.33 & 10.15 & 182.8 \\
\hline \multirow{3}{*}{50} & 120 & 0.153 & 41.52 & 11.05 & 136.0 \\
\hline & 150 & 0.070 & 52.47 & 10.21 & 276.2 \\
\hline & 180 & 0.075 & 53.38 & 10.02 & 284.3 \\
\hline
\end{tabular}

\subsection{Chemical properties}

FTIR of the LBPFA was shown in Fig.8 and typical peaks of the adhesive were presented in Table 3. In fact, the peak of $\mathrm{O}-\mathrm{H}$ bonding was observed at wavenumber of $3410.10 \mathrm{~cm}^{-1}$. Wavenumbers of 1587.41 and $1457.16 \mathrm{~cm}^{-1}$ were reported as

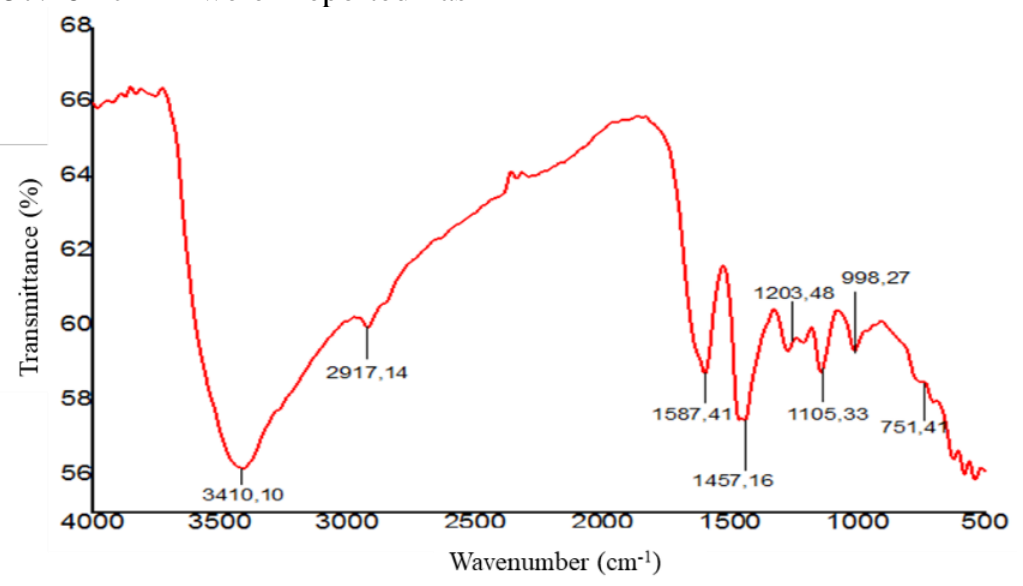

Fig. 8. FT-IR spectra of coir pith LBPFA

Table 3. FT-IR bands assignment in LBPFA

\begin{tabular}{llll}
\hline $\begin{array}{l}\text { Wavenumber } \\
\left(\mathbf{c m}^{-1}\right)\end{array}$ & $\begin{array}{l}\text { Wavenumber of the } \\
\text { LBPFA }\left(\mathbf{c m}^{-1}\right)\end{array}$ & Functional Group & $\begin{array}{l}\left.\text { Wavenumber(cm- } \mathbf{1}^{\mathbf{1}}\right) \\
\text { (Wang et al., 2009) }\end{array}$ \\
\hline $3440-3350$ & 3410.10 & $\mathrm{O}-\mathrm{H}($ phenolic $\mathrm{OH}$ and aliphatic $\mathrm{OH})$ & 3350 \\
$3981-2887$ & 2917.14 & $\mathrm{C}-\mathrm{H}\left(\mathrm{CH}_{3}\right.$ and $\left.\mathrm{CH}_{2}\right)$ & $3020 ; 2960$ \\
$1600-1450$ & $1587.41 ; 1457.16$ & Aromatic rings & $1600 ; 1500 ; 1450$ \\
$1260-1100$ & $1203.48 ; 1105.33$ & Ar- $\mathrm{CH}_{2} \mathrm{OH}$ & 1100 \\
$1000-690$ & $998.27 ; 751.41$ & Ar-C-H & - \\
\hline
\end{tabular}

\subsection{Thermal properties}

Differential scanning calorimetry analysis of LBPFA at the room temperature of $25^{\circ} \mathrm{C}$ to $180^{\circ} \mathrm{C}$ was shown in Fig. 9. A heat collecting tip from room temperature to $180^{\circ} \mathrm{C}$ was obtained. The peak of the cure was $115.6^{\circ} \mathrm{C}$, which was low compared to range of $130-180^{\circ} \mathrm{C}$ reported by Pflugen (Pfungen, 2015). The low solidified temperature of the bondings of aromatic rings in lignin. Besides, Ar$\mathrm{CH}_{2} \mathrm{OH}$ bondings were observed at wavenumber of 1203.48 and $1105.33 \mathrm{~cm}^{-1}$. The peaks at 998.27 and $751.41 \mathrm{~cm}^{-1}$ were bondings of Ar-C-H. These peaks were also presented in the previous study of Wang (Wang et al., 2009). 


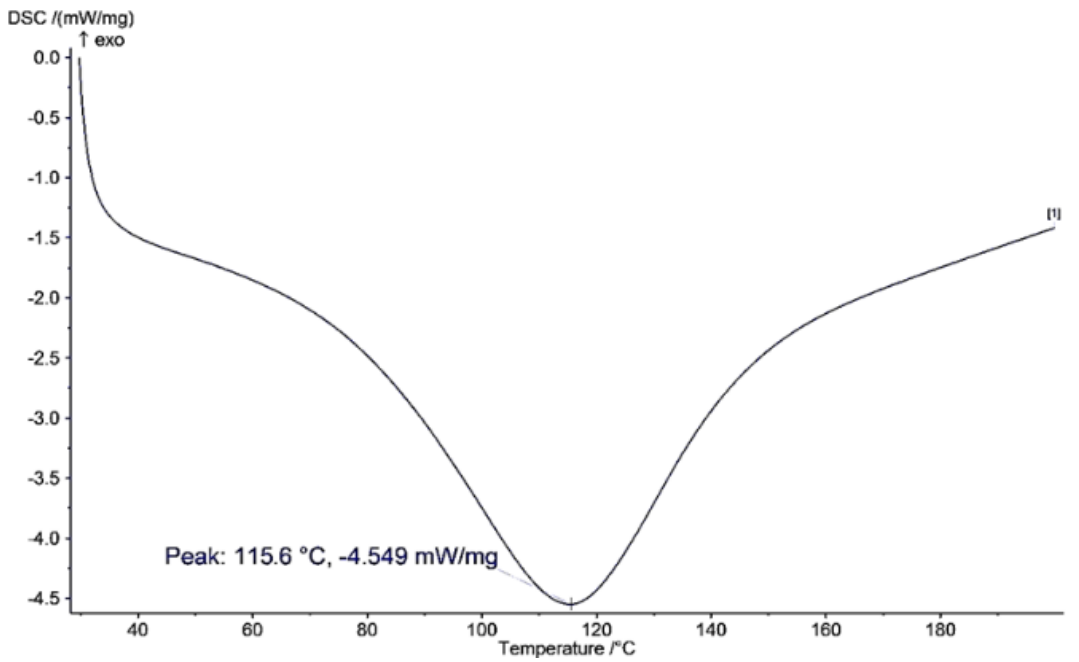

Fig. 9. DSC curve of coir pith LBPFA

\subsection{Adhesive mechanical performance}

Fig. 10 showed that tensile strength of LBPFA increased according to increasing the content of lignin in the range of $30-40 \%$. However, the tensile strength decreased as long as increasing lignin content to $50 \%$. Both dry and wet tensile strengths respectively reached the peaks at 14.42 and 7.66 $\mathrm{MPa}$ as $40 \%$ replaced lignin content was used. Moreover, the viscosity of the adhesive with $40 \%$ lignin content was $185 \mathrm{cP}$, which was good for the bonding of two wood panel surfaces. The decrease in tensile strength as increasing lignin content to
$50 \%$ would be caused by high viscosity and high solid content making it hard to evenly spread adhesive on the board surface. In this study, another common commercial glue being applied on construction and interior was also compared. The results showed that the glue's tensile strength was very low (2.28 MPa) and its waterproofing capacity was not compared to synthetic LBPFA.

Generally, the tensile strength of LBPFA was high and the value of dry tensile modulus was higher than that of the wet tensile modulus. The detailed results were shown in Fig. 11.

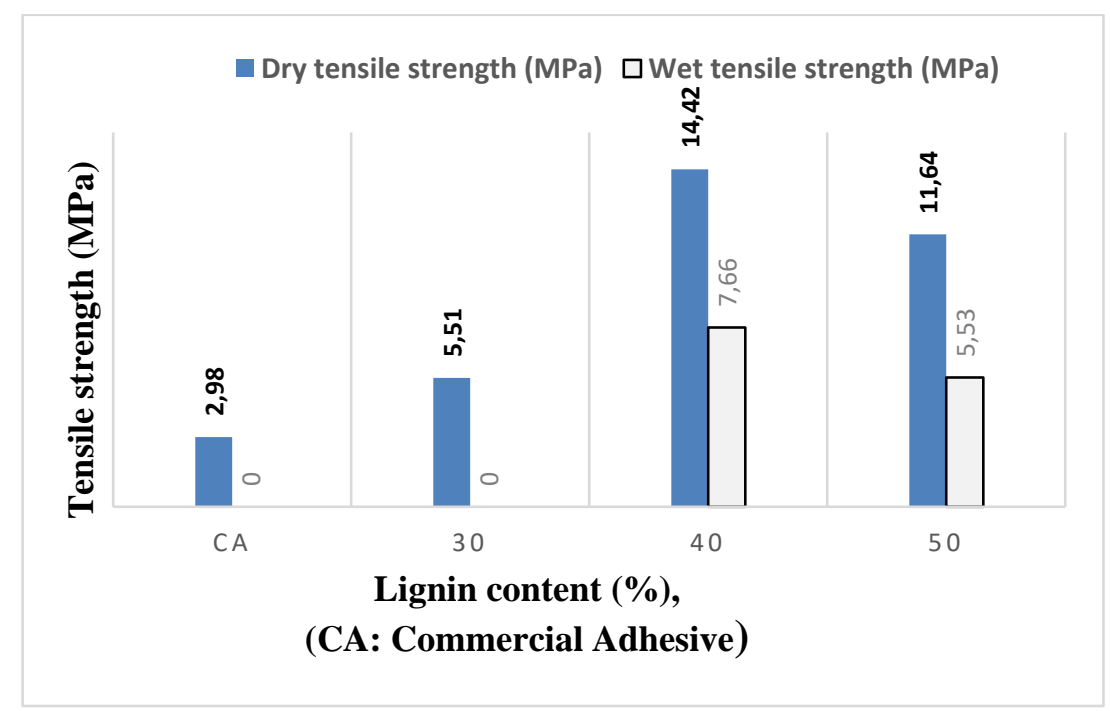

Fig. 10. Tensile strength of CA and LBPFA

The results of bonding ability on artificial plywood between synthetic LBPFA and commercial glue were $15.97 \mathrm{MPa}$ and $20.16 \mathrm{MPa}$, respectively. Both showed high tensile strain-stress behaviors although tensile strain-stress of the commercial product was slightly higher than that of LBPFA. However, the 
amount of LBPFA applied was low $\left(200 \mathrm{~g} . \mathrm{m}^{-2}\right)$, it was easy to use, evenly distributed on the board surface, only $0.36 \%$ error which indicated its uniform. LBPFA had good waterproofing ability. However, the process of pressing and treating the sample needs to use heat to create bonds better. In the case of commercial ones, a large amount of glue $\left(400\right.$ g. $\left.\mathrm{m}^{-2}\right)$ was required. In addition, commercial glue was too condensed to spread out evenly on the wood surface (about $0.58 \%$ error), no water resistance but there was no need to use heat once making press.

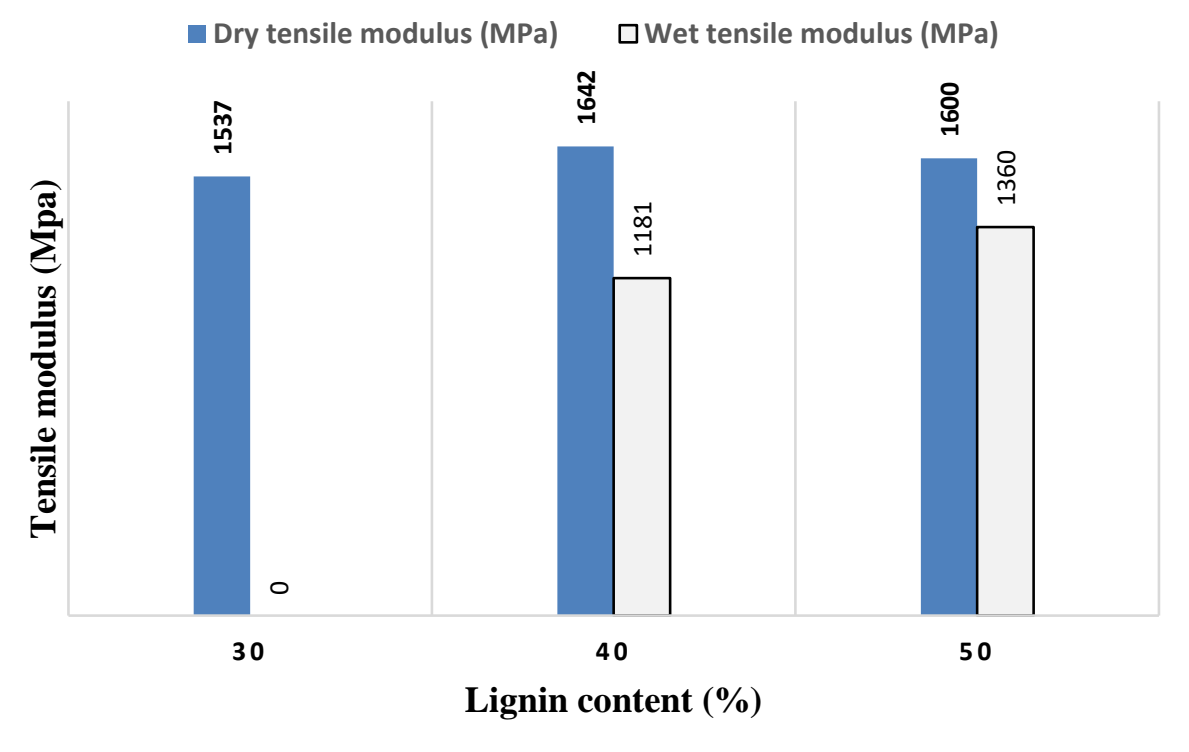

Fig. 11. Tensile modulus of LBPFA

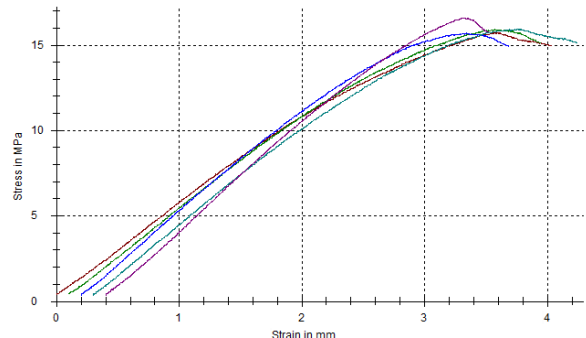

(a)

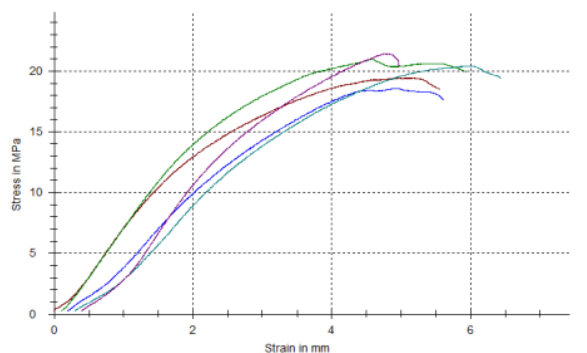

(b)

Fig. 12. Tensile strain-stress behavior of (a) LBPFA and (b) commercial glue on artificial plywood

\section{CONCLUSION}

Resol-type LBPFA was successfully synthesized from coir pith lignin with the replacement of lignin on phenol in the range of 30\%-50\% total amount of phenol. The optimal conditions in the synthesis process: lignin content, reaction temperature,

\section{REFERENCES}

Cetin, N. S., \& Ozmen, N. (2003). Studies on ligninbased adhesives for particleboard panels. Turkish Journal of Agriculture and Forestry, 27(3), 183-189.

Derek, S. (2008). Lignin as a base material for materials applications: Chemistry, application and econimics. reaction time was $40 \%$ (wt/wt), $90{ }^{\circ} \mathrm{C}, 180$ minutes, respectively. At the optimal conditions, the highest value of the tensile strength was 14.42 MPa. LBPFA was successfully applied on natural wood and artificial plywood and showed outstanding results compared to commercial ones.

Industrial Crops and Products, 27(2), 202-207. https://doi.org/10.1016/j.indcrop.2007.07.008

Duval, A., \& Lawoko, M. (2014). A review on ligninbased polymeric, micro and nano-structured materials, Reactive and Functional Polymers, 85, 78-96. https://doi.org/10.1016/j.reactfunctpolym.2014.09.017 
Hemmila, V., Trischler, J., \& Sandberg, D. (2013, September 11-12). Lignin - an adhesive raw material of the future or waste of research energy [Conference presentation]. Nineth Meeting of the Northern European Network for Wood Science and Engineering (WSE), Hannover, Germany.

Ibrahim, M. N. M., Zakaria, N., Sipaut, C. S., Sulaiman, O., \& Hashim, R. (2011). Chemical and thermal properties of lignins from oil palm biomass as a substitute for phenol in a phenol formaldehyde resin production. Carbohydrate Polymers, 86(1), 112-119. https://doi.org/10.1016/j.carbpol.2011.04.018

Kalami, S., Arefmanesh, M., Master, E., \& Nejad, M. (2017). Replacing $100 \%$ of phenol in phenolic adhesive formulations with lignin. Journal of applied polymer science, 134(30), 1-9. https://doi.org/10.1002/app.45124

Liitia, T. (2014). Pro Lignin - High-Value Products from Lignin Side-Streams of Modern Biorefineries [Conference presentation]. Sixth Wood Wisdom-Net Research Programme Seminar, Hanover, Germany.

Luong, H. V. T., Nguyen, T. N. Y., Truong., H. T., Nguyen, T. V., \& Nguyen, H. T. (2017). Lignin derived from coir pith: Extraction process and characterization. Vietnam Journal of Chemistry, 55(5E34), 531-536.

Mainka, H., Tager, O., Korner, E,. Hilfert, L., Busse, S., Edelmann, F. T., \& Herrmann A. S. (2015). Lignin an alternative precusor for sustainable and costeffective automotive carbon fiber, Journal of Materials Research and Technology, 4(3), 283-296. https://doi.org/10.1016/j.jmrt.2015.03.004

Mansori, N. E. E., \& Salvado, J. (2006). Structural characterixzation of technical lignins for the production of adhesives: Application to lignosulfonate, kraft, soda-anthraquinone, organosolv and ethanol process lignins, Industrial
Crops and Products, 24(1), 8-16.

https://doi.org/10.1016/j.indcrop.2005.10.002

Nguyen, T. N. Y., Nguyen, T. V., \& Luong, H. V. T., (2018). Fabrication of coir pith lignin-based fibers using electrospining method. International Journal of Scientific Engineering and Science, 2(1), 2456-7361.

Norgren, M., \& Edlund, H. (2014). Lignin: recent advances and emerging applications, Current opinion in colloid \& interface science, 19(5), 409416. https://doi.org/10.1016/j.cocis.2014.08.004

Ozmen, N. (2000). Lignin Based Adhesives for Particleboard Production (doctoral dissertation), Bangor University.

Pfungen, L. (2015). Lignin Phenol Formaldehyde Wood Adhesives (master's thesis). University of Natural Resources and Life Sciences, Vienna.

Tejado, A., Pena, C., Labidi, J., Echeverria, J. M., \& Mondragon, I. (2007). Physico-chemical characterization of lignins from different sources for use in phenol-formaldehyde resin synthesis. Bioresources Technology, 98(8), 1655-1663. https://doi.org/10.1016/j.biortech.2006.05.042

Wang, M., Leitch, M., \& Xu, C. (2009). Synthesis of phenol-formaldehyde resol resins using organosolv pine lignins. European Polymer Journal, 45(12), 3380-3388. https://doi.org/10.1016/j.eurpolymj.2009.10.003

Yang, S., Zhang, Y., Yuan, T. Q., \& Sun, R. C. (2015). Lignin-phenol-formaldehyde resin adhesives prepared with biorefinery technical lignins. Journal of Applied Polymer Science, 132(36), 1-9. https://doi.org/10.1002/app.42493

Zakaria, N. B. (2015). Formulation and characterization of lignin-phenol-formaldehyde resins for plywood (master's thesis), University Sains Malaysia. 